\title{
Experimental Validation of a New Cost- Effective and Nonintrusive BTU Meter
}

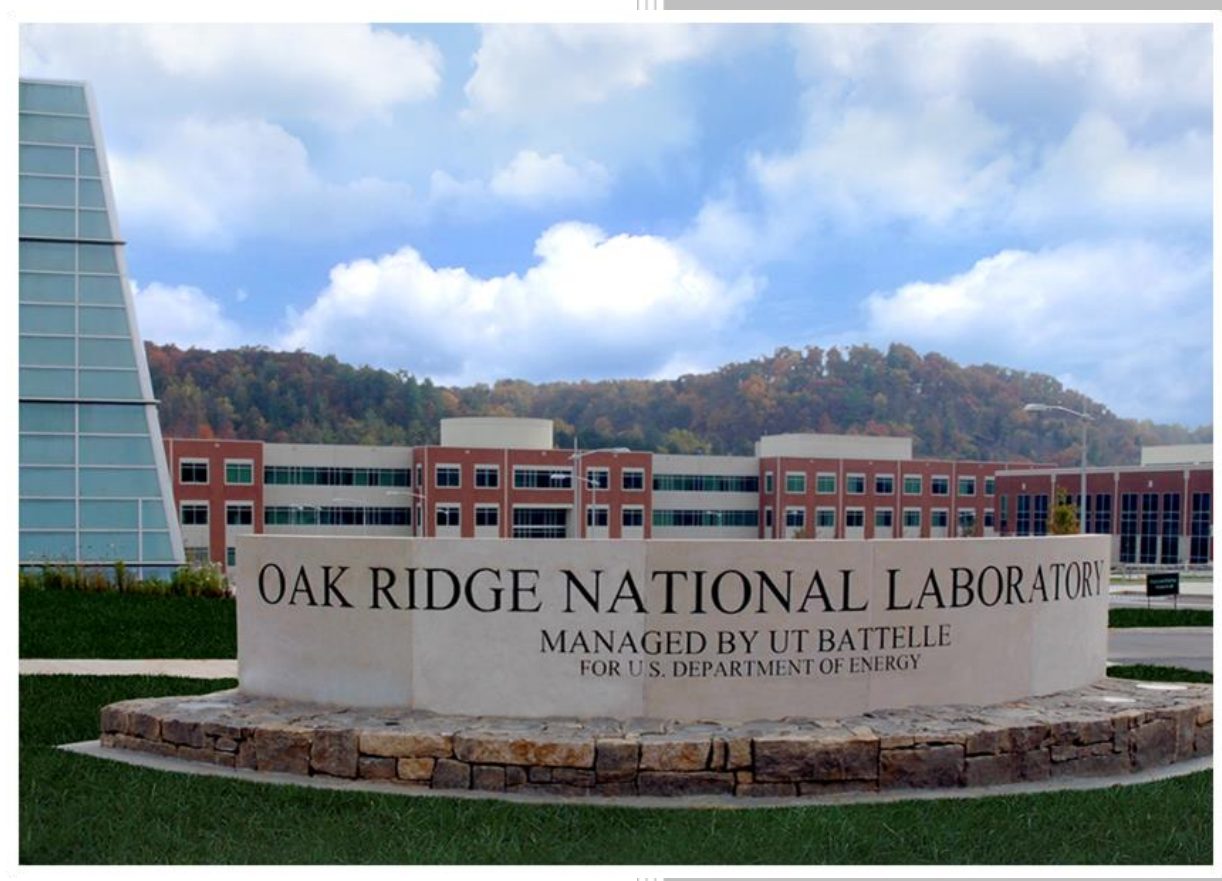

Approved for public release.

Distribution is unlimited.

Xiaobing Liu Som Shrestha

Rande Cherry

Chris Cirenza

Shyam Krishna Shenoy

Aditya Narayan

CRADA final report for

CRADA number NFE-17-06777

September 2018 


\section{DOCUMENT AVAILABILITY}

Reports produced after January 1, 1996, are generally available free via US Department of Energy (DOE) SciTech Connect.

Website www.osti.gov

Reports produced before January 1, 1996, may be purchased by members of the public from the following source:

National Technical Information Service

5285 Port Royal Road

Springfield, VA 22161

Telephone 703-605-6000 (1-800-553-6847)

TDD 703-487-4639

Fax 703-605-6900

E-mail info@ntis.gov

Website http://classic.ntis.gov/

Reports are available to DOE employees, DOE contractors, Energy Technology Data Exchange representatives, and International Nuclear Information System representatives from the following source:

Office of Scientific and Technical Information

PO Box 62

Oak Ridge, TN 37831

Telephone 865-576-8401

Fax 865-576-5728

E-mail reports@osti.gov

Website http://www.osti.gov/contact.html

This report was prepared as an account of work sponsored by an agency of the United States Government. Neither the United States Government nor any agency thereof, nor any of their employees, makes any warranty, express or implied, or assumes any legal liability or responsibility for the accuracy, completeness, or usefulness of any information, apparatus, product, or process disclosed, or represents that its use would not infringe privately owned rights. Reference herein to any specific commercial product, process, or service by trade name, trademark, manufacturer, or otherwise, does not necessarily constitute or imply its endorsement, recommendation, or favoring by the United States Government or any agency thereof. The views and opinions of authors expressed herein do not necessarily state or reflect those of the United States Government or any agency thereof. 
Energy and Transportation Science Division

\title{
EXPERIMENTAL VALIDATION OF A NEW COST-EFFECTIVE AND NONINTRUSIVE BTU METER
}

\author{
Xiaobing Liu, $\mathrm{PhD}$ \\ Som Shrestha, $\mathrm{PhD}$ \\ Rande Cherry \\ Chris Cirenza \\ Shyam Krishna Shenoy \\ Aditya Narayan
}

Date Published: September 2018

\author{
Prepared by \\ OAK RIDGE NATIONAL LABORATORY \\ Oak Ridge, Tennessee 37831-6283 \\ managed by \\ UT-BATTELLE, LLC \\ for the \\ US DEPARTMENT OF ENERGY \\ under contract DE-AC05-00OR22725
}





\section{CONTENTS}

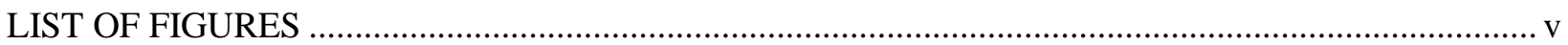

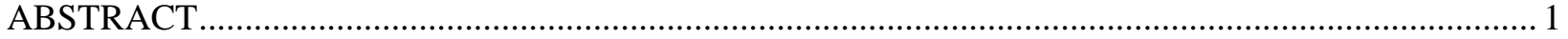

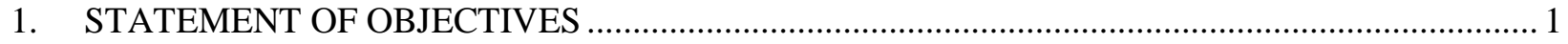

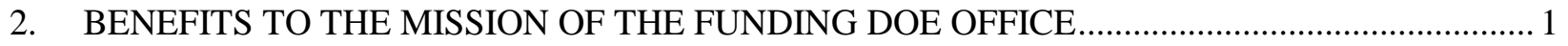

3. TECHNICAL DISCUSSION OF WORK PERFORMED BY ALL PARTIES …........................... 2

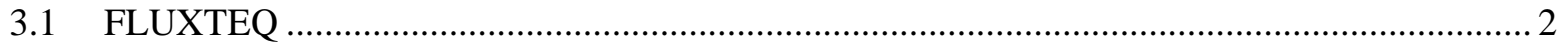

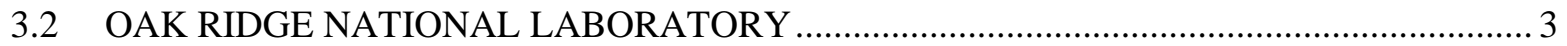

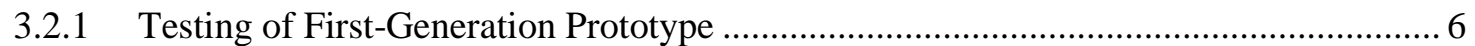

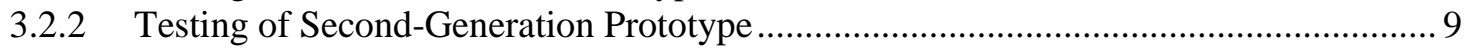

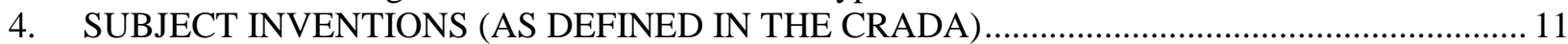

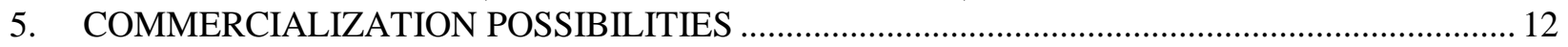

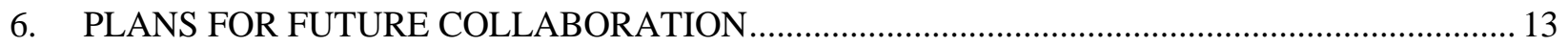

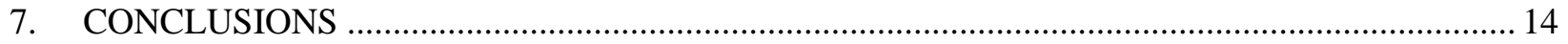

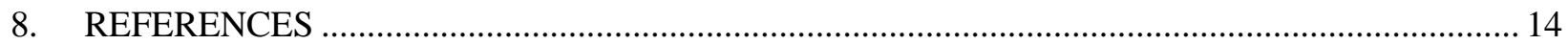





\section{LIST OF FIGURES}

Figure 1. Hydronic piping system located at ORNL's Flexible Research Platform.........................3

Figure 2. A hydronic piping system located at ORNL's Flexible Research Platform.......................4

Figure 3. Two commercial flow meters and three FluxTeq flow meters installed on a 2 in.

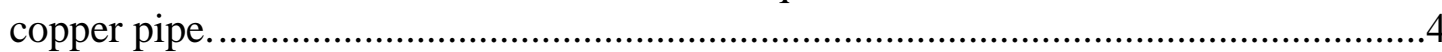

Figure 4. Measured heat flux and temperature in response to heater cycling on a loop with a fixed flow rate. ...............................................................................................

Figure 5. Measured heat flux and temperature in response to heater cycling at various flow

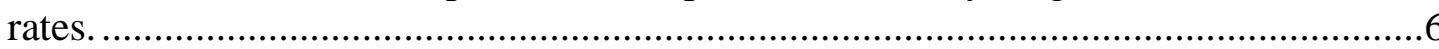

Figure 6. Correlation between the convection heat transfer coefficient and flow rate using a power curve, calculated using November data ............................................................

Figure 7. Correlation between the convection heat transfer coefficient and flow rate using a logarithmic curve, calculated using combined November and December data..............8

Figure 8. Correlation between $\mathrm{Nu}$ and Re derived from the measured convection heat transfer coefficients and flow velocity in a 2 in. copper pipe with water flowing through it.....

Figure 9. Second prototype FluxTeq sensors (prefabricated and easier to install).......................10

Figure 10. Correlation between $\mathrm{Nu}$ and Re derived from the measured convection heat transfer coefficients and flow rates on copper pipes with different diameters

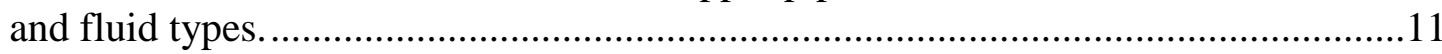

Figure 11. The sensor configuration. ..................................................................................

Figure 12. Approximate price range of various flow meters. Each column indicates the average price of flow meters in each category, and the error bars show the range of the price. 



\begin{abstract}
This report summarizes the research conducted under a Collaborative Research and Development Agreement with FluxTeq LLC for experimental validation of a new inexpensive and nonintrusive thermal energy meter (referred as a BTU meter). BTU meters measure thermal energy flows in energy systems (e.g., chillers or boilers); measurements of these flows are essential for performance monitoring, fault detection and diagnostics, and control of these energy systems. The key component of a BTU meter is the device for measuring flow rate. Most flow rate meters available today are either intrusive and difficult to install, especially on existing energy systems, or built around sophisticated, very expensive ultrasonic sensors. As a result, BTU meters are not yet commonly used in building energy systems to more precisely control heating, ventilation, and air-conditioning (HVAC) systems and make them operate more energyefficiently. Considering that HVAC systems consume about $40 \%$ of the energy used in residential and commercial buildings and that advanced HVAC controls have the potential to significantly reduce the energy consumption of HVAC systems, there is a very large potential market for BTU meters. FluxTeq has developed a new flow rate sensor that takes an innovative thermal measurement approach to determining flow rate in a nonintrusive way at low cost. Test results from this project indicate that the new sensor can measure the flow rates of different fluids in copper pipes of various sizes. The difference between the flow rates measured with the new sensor and with a calibrated commercial magnetic flow meter is less than $10 \%$. The estimated price of the new flow rate sensor is around $\$ 250$ - at least $50 \%$ lower than the average price of other flow meters currently available on the market. Further development is needed to improve the accuracy and repeatability of flow rate measurement, to enable real-time measurement, and to increase the tolerance for variable flow rate and temperature.
\end{abstract}

\title{
1. STATEMENT OF OBJECTIVES
}

The objectives of this Collaborative Research and Development Agreement (CRADA) project are to improve the design of the FluxTeq BTU (British thermal unit, a measure of heat) meter and test its performance using Oak Ridge National Laboratory's (ORNL) Flexible Research Platform. The research will help complete the final stages of product development necessary to take this product to market. Successful development of an inexpensive product will have a significant impact on the current BTU meter and flow meter market. This will enable more widespread use of BTU meters and flow meters for submetering of the performance of heating, ventilation, and air-conditioning (HVAC) systems, leading to better controlled and more efficient HVAC systems.

\section{BENEFITS TO THE MISSION OF THE FUNDING DOE OFFICE}

Building equipment efficiency plays an important role in achieving US energy security. According to the most recent Energy Information Administration (EIA) estimates, residential and commercial buildings will consume 38.22 quads of energy - $37.6 \%$ of total US primary energy consumption - in 2030, continuing to exceed industrial and transportation energy consumption. About $40 \%$ of the energy consumed in buildings is used to provide space heating, water heating, and air-conditioning (EIA 2018a, 2018b). BTU meters can measure the amount of thermal energy being delivered to a building by its HVAC systems. Integrating BTU meters into the HVAC control system can improve performance monitoring and thus enable more advanced controls, as well as fault detection and diagnostics. Improved monitoring and advanced controls have the potential to increase the operational energy efficiency of HVAC systems by up to 30\% (Treado and Chen 2013). However, current commercially available BTU meters are expensive (some costing thousands of dollars) or intrusive and difficult to install, especially at existing HVAC equipment. Their cost prevents widespread use of BTU meters in HVAC control systems. The focus of this project is to improve and validate the performance of an inexpensive, nonintrusive BTU 
meter. Cost-effective BTU meters will help facilitate more effective monitoring and control of HVAC systems and thus help to meet the Department of Energy (DOE) Building Technologies Office goal of $30 \%$ energy savings by 2030 .

\section{TECHNICAL DISCUSSION OF WORK PERFORMED BY ALL PARTIES}

A BTU meter consists of a sensor to measure the flow rate of a heat carrier liquid, a pair of temperature sensors to measure the temperature differential across a heat exchange circuit, and a device to calculate the heat exchange rate. Temperature sensors are readily available and inexpensive. Therefore, the focus of this project is on the device to measure flow rate.

FluxTeq, a small business that developed an inexpensive, nonintrusive flow meter, partnered with ORNL through a Small Business Voucher program to evaluate the performance of its new flow rate sensor in real-world applications. In this CRADA project, ORNL conducted a series of tests with two generations of prototype flow rate sensors and provided feedback to FluxTeq for further improving the sensor. FluxTeq assisted in the tests and improved the prototype based on ORNL's feedback. The technical work performed by FluxTeq and ORNL is discussed below.

\subsection{FLUXTEQ}

FluxTeq developed prototypes of the new flow rate sensors and installed them at ORNL's Light Commercial Building Flexible Research Platform (LCB-FRP) test facility. The new flow rate sensor is based on the correlation between the velocity of a turbulent pipe flow and the convection heat transfer coefficient inside the pipe. The prototype flow meter tested in this project consisted of a FluxTeq standard heat flux sensor, a modified thermocouple (TC) temperature sensor, and a thin-film resistance heater. To minimize the contact resistance arising from the TC's thickness and its soldered ends, thin foils of constantine and copper were attached to the ends of the corresponding wires of a TC. As shown in Figure 1, the thin foils of constantine and copper were placed against the outer surface of a metal pipe; a heat flux sensor was placed on top of the TC; and the assembly was wrapped with a thin film in which an electric resistance heater was embedded. The FluxTeq flow rate sensor is flexible and can easily be mounted on a pipe using a compression wrap or a clamping tool.

The electric heater of the prototype is powered with a $50 \mathrm{~V} \mathrm{DC}$ power supply, which was cycled on and off automatically at regular intervals (e.g., every 60 seconds) through an Arduino controller. Power supply voltage to the heaters and heater on/off time was adjusted as needed.

The FluxTeq flow rate sensor unintrusively measured the flow rate by analyzing the temperature change of the pipe wall (where the heater is installed) in response to a thermal shock (i.e., when the heater was turned on). The analysis included the following steps:

- Determine the convection heat transfer coefficients $(h)$ and contact resistances $(R)$ at a series of known flow rates with a parameter estimation approach, which is to find a combination of the $h$ and $R$ values that resulted in the minimum error between the measured and model-predicted pipe wall temperature (Alshawaf 2018).

- Derive a nondimensional correlation between the determined $h$ values (normalized with the Nusselt number $[\mathrm{Nu}]$ ) and the known velocity of the flow (normalized with the Reynolds number $[\mathrm{Re}]$ ).

- Measure other unknown flow rates based on the $h$ values determined with step 1 and the nondimensional correlation derived in step 2 . 
FluxTeq installed 16 flow meters at the experimental facility in ORNL and determined flow rates based on the measured temperature and heat flux data at various conditions.

\section{Major components \\ - Thermocouple \\ - Heat flux sensor \\ - Heater + power supply \\ - Data acquisition system}

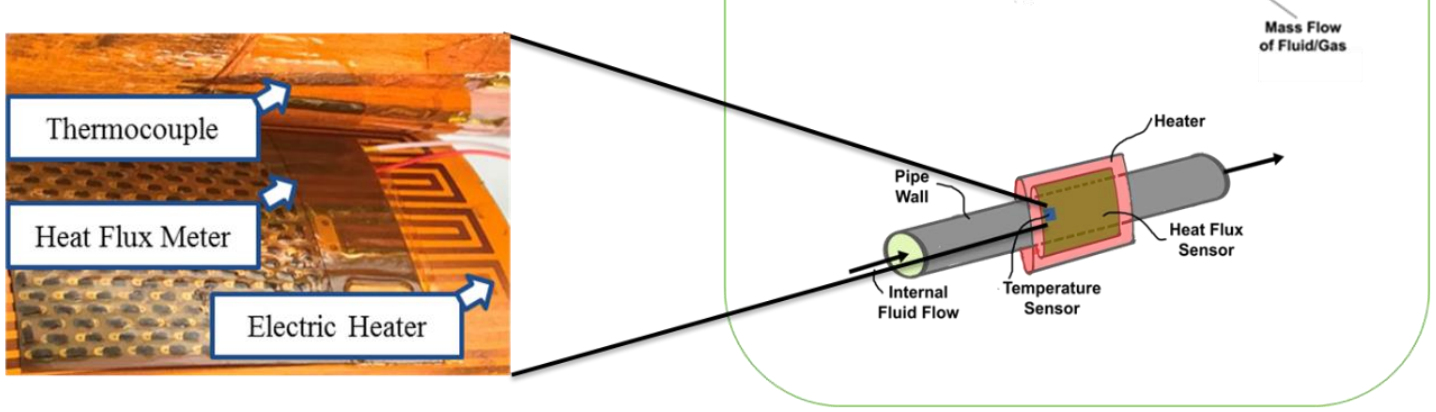

Figure 1. Hydronic piping system located at ORNL's Flexible Research Platform

\subsection{OAK RIDGE NATIONAL LABORATORY}

Researchers at ORNL conducted a series of tests in the LCB-FRP to evaluate the performance of various configurations of the FluxTeq flow rate sensor. These tests included a range of flow rates, in pipes with various diameters, and with water and an aqueous solution of propylene glycol as the heat carrier fluid. Based on the test results, ORNL provided feedback to FluxTeq, along with recommendations for further improving the sensor configuration and the algorithm for determining the $h$ in the pipe.

For the initial evaluation, four sets of the first prototype FluxTeq flow meters were installed on an experimental hydronic piping system in the LCB-FRP. The hydronic piping system (Figure 2) consisted of one main loop and four subloops located in different zones. The existing data acquisition system at LCB-FRP can measure performance data from more than 100 sensors - including flow rates and temperatures (return and supply) in the main loop and each of the four subloops - and visualize them in real time. To cross check the flow rate measurement in the main loop, an ultrasonic flow meter (Micronics U1000) was installed in series with an existing magnetic flow meter Omega (FMG3001), as shown in Figure 3. The manufacturer-specified linearity and repeatability of the magnetic flow meter (Omega FMG3001) were $\pm 1 \%$ of the reading and $\pm 0.5 \%$ of the reading, respectively. The magnetic flow meter was calibrated at ORNL's Metrology Laboratory. The manufacturer-specified accuracy of the ultrasonic flow meter (Micronics U1000) was $\pm 3 \%$ of the flow reading for a flow rate $>0.3 \mathrm{~m} / \mathrm{s}$, corresponding to a 9.5 gallon per minute (gpm) flow rate in a 2 in. (nominal diameter) pipe. The readings from the two commercial flow meters matched well except during rapid changes in flow rate, at which points the ultrasonic flow meter read erroneous data.

Flow rate and temperature measurements were recorded with a Campbell Scientific CR3000 data logger, along with all the measurements from the FluxTeq sensors (temperature and heat flux). These data were recorded at $1 \mathrm{~Hz}$ frequency. All the FluxTeq sensors were wrapped with approximately $1 / 2$ in. thick insulation to minimize heat loss to the ambient. Three different sensor configurations were tested: 
1. Small gap between TC plates and a large heater

2. Connected TC plates and a large heater

3. Connected TC plates and a small heater

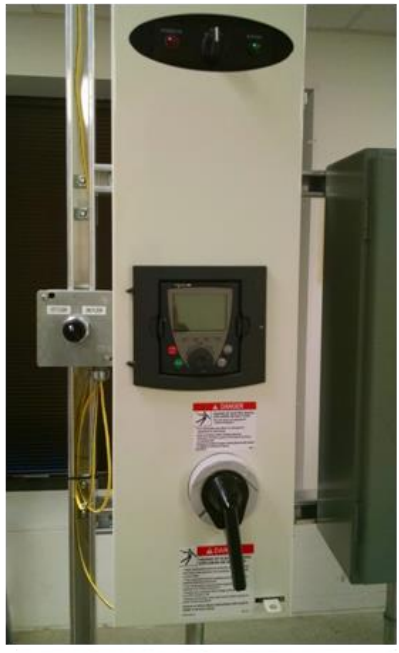

Variable frequency drive
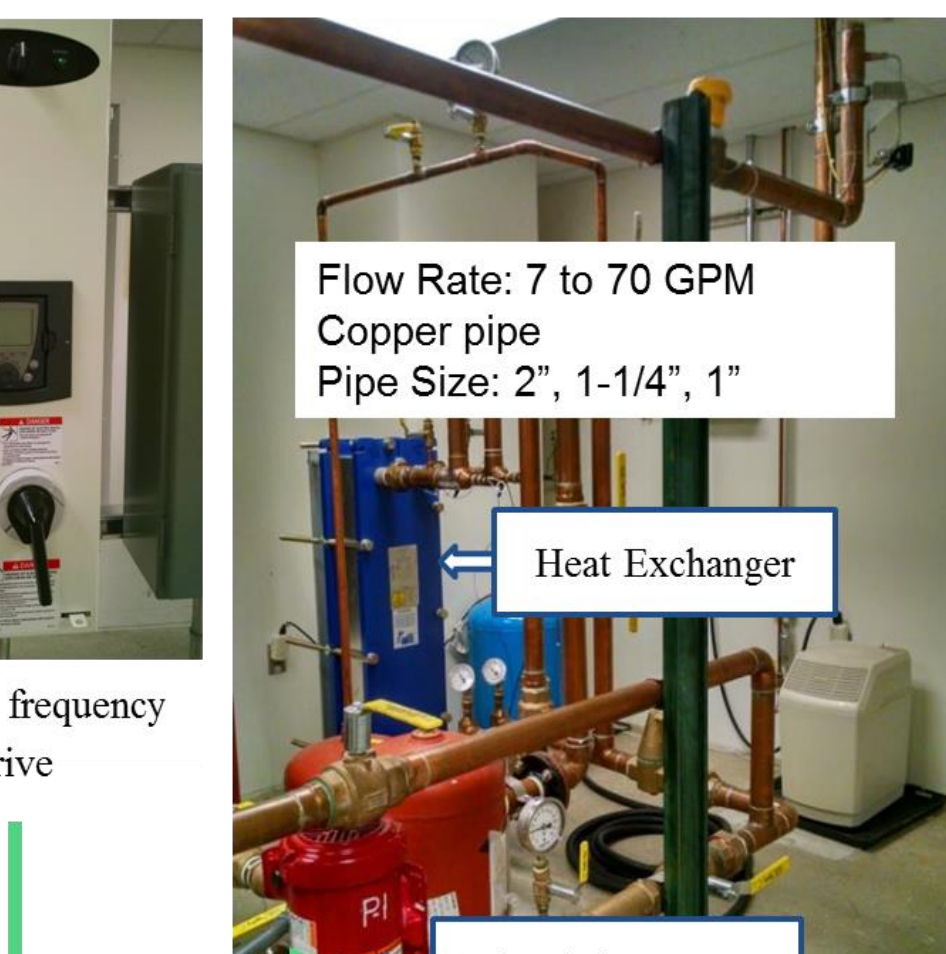

Flow Rate: 7 to 70 GPM Copper pipe

Pipe Size: 2", 1-1/4", 1"

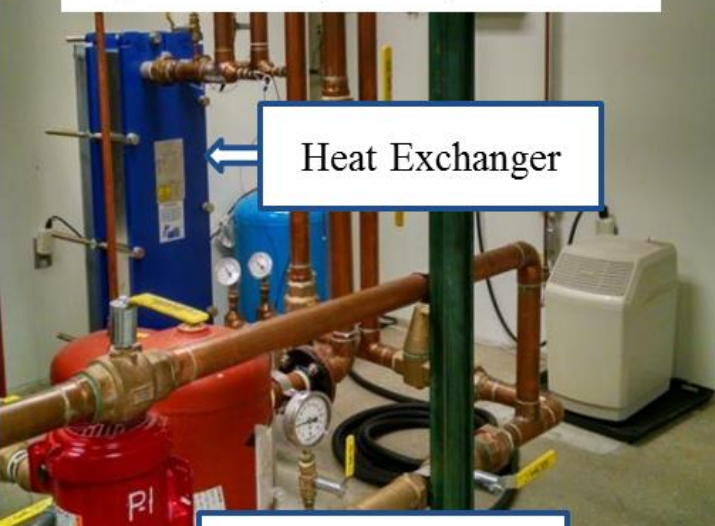

Circulation Pump

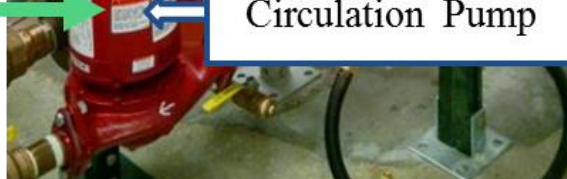

Figure 2. A hydronic piping system located at ORNL's Flexible Research Platform.

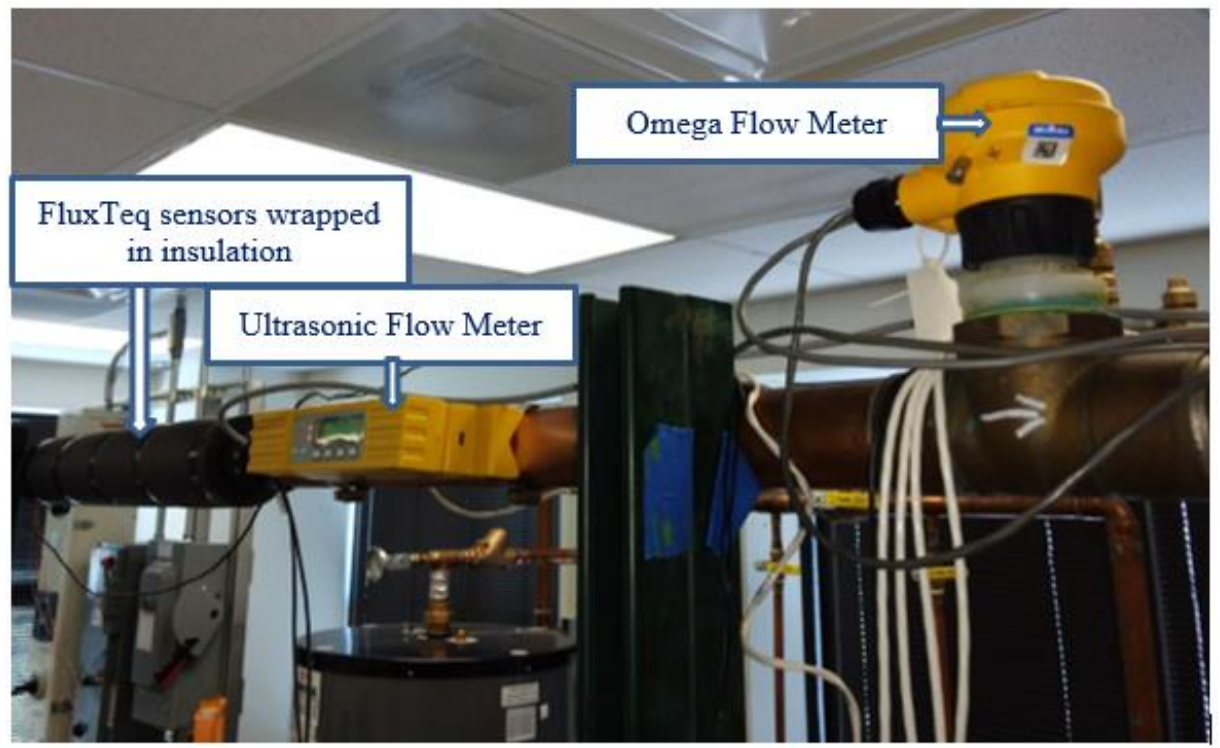

Figure 3. Two commercial flow meters and three FluxTeq flow meters installed on a 2 in. copper pipe. 
FluxTeq flow rate sensors with those three configurations (sensors \#1 through \#3) were mounted on the supply line of the piping system (as indicated in Figure 3), and a flow rate sensor (sensor \#4) with the third configuration was mounted after a $90^{\circ}$ elbow in the return line of the piping system (not shown in Figure 3). The pipe on which the sensors were installed was Type L copper tube of $2 \mathrm{in}$. nominal diameter (inner diameter of the pipe was 1.985 in., wall thickness was 0.07 in.). Water was circulated with a variable-speed pump in this piping system. Each flow rate sensor was connected to an electric power supply, which was controlled to cycle on and off at a fixed frequency. Figure 4 shows the measured temperature and heat flux in response to the on-and-off cycling of the resistance heater embedded in the sensor; the flow rate was fixed.
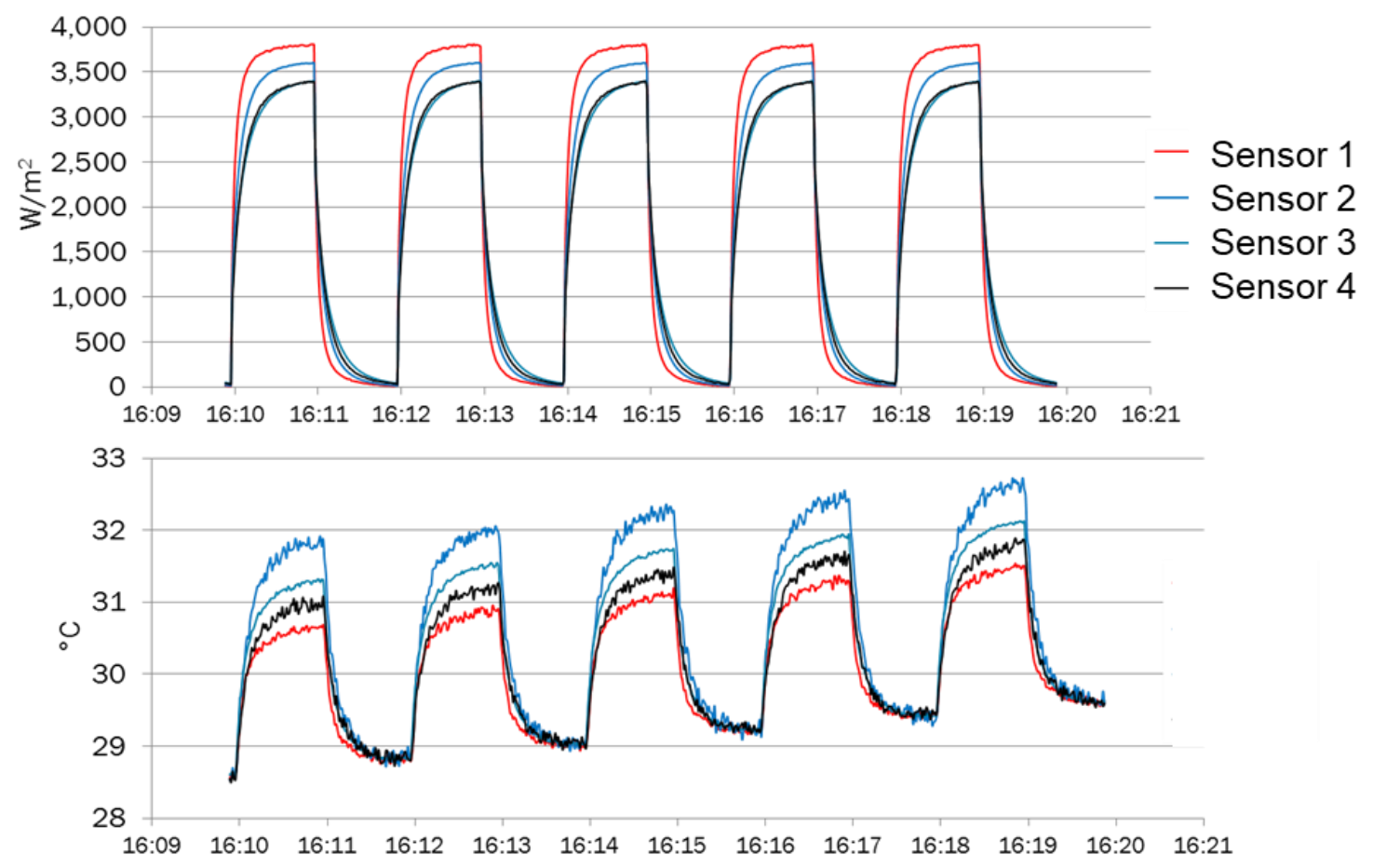

Figure 4. Measured heat flux and temperature in response to heater cycling on a loop with a fixed flow rate.

Initial tests were conducted at several flow rates. Figure 5 shows the temperature and heat flux response as a function of flow rate. Whereas the heat flux did not change much, the temperature change varied from $\sim 1.5$ to $\sim 2.7 \mathrm{~K}$ as the flow rate changed from 45.8 to $8.06 \mathrm{gpm}$. The change in the temperature rise as a function of the flow rate indicated that flow rate can be determined by measuring the temperature rise resulting from a given heat flux. 


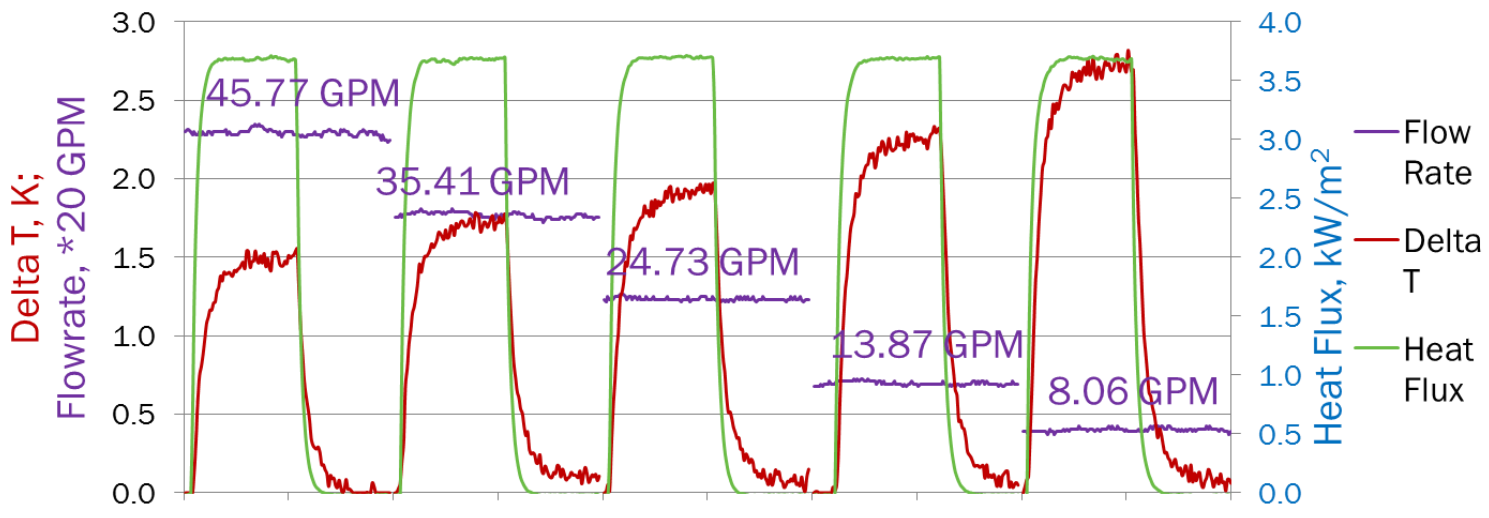

Figure 5. Measured heat flux and temperature in response to heater cycling at various flow rates.

\subsubsection{Testing of First-Generation Prototype}

Two sets of tests were conducted to evaluate the performance of the FluxTeq flow rate sensor. These tests were conducted in November through December of 2017 using the following procedure:

- Run the hydronic piping system at various flow rates.

- Measure temperature and heat flux at each of the four FluxTeq flow rate sensors, and the flow rate in the pipe using the two commercial flow meters.

The measured data were sent to FluxTeq along with other information, such as pipe size, material, and other parameters. FluxTeq explored two methods to establish the correlation between the $h$ and the measured flow rates, including (1) a power curve trend (first iteration) and (2) a logarithmic curve trend (second iteration). Details of the tests and the performance of the FluxTeq flow rate sensor are discussed in the following subsections.

\subsubsection{Testing in November 2017}

Tests were conducted at four different flow rates. A heater controller was set to turn the heaters on and off cyclically every 60 seconds. Power inputs to the heaters were set at 18.5 Watts. FluxTeq used both transient and steady state experimental data to calculate the $h$ between the pipe inner surface and the heat carrier fluid, and the contact resistance $R$ between the TC and the outer surface of the pipe. It was found that the $R$ was comparable to the convection heat transfer resistance $(1 / h)$. On the other hand, the thermal resistance of the copper tube was $4.43 \mathrm{E}-6 /\left(\mathrm{m}^{2} \cdot \mathrm{K}\right) / \mathrm{W}$, which is approximately two orders of magnitude smaller than the $R$ and the convection heat transfer resistance. Figure 6 shows the correlation between the $h$ and flow rate, calculated using the November data. Note that a power curve was used to establish this correlation. Among the four arrangements, sensor \#1 gave the best results. Therefore, only the data from sensor \#1 are presented in Figure 6. 


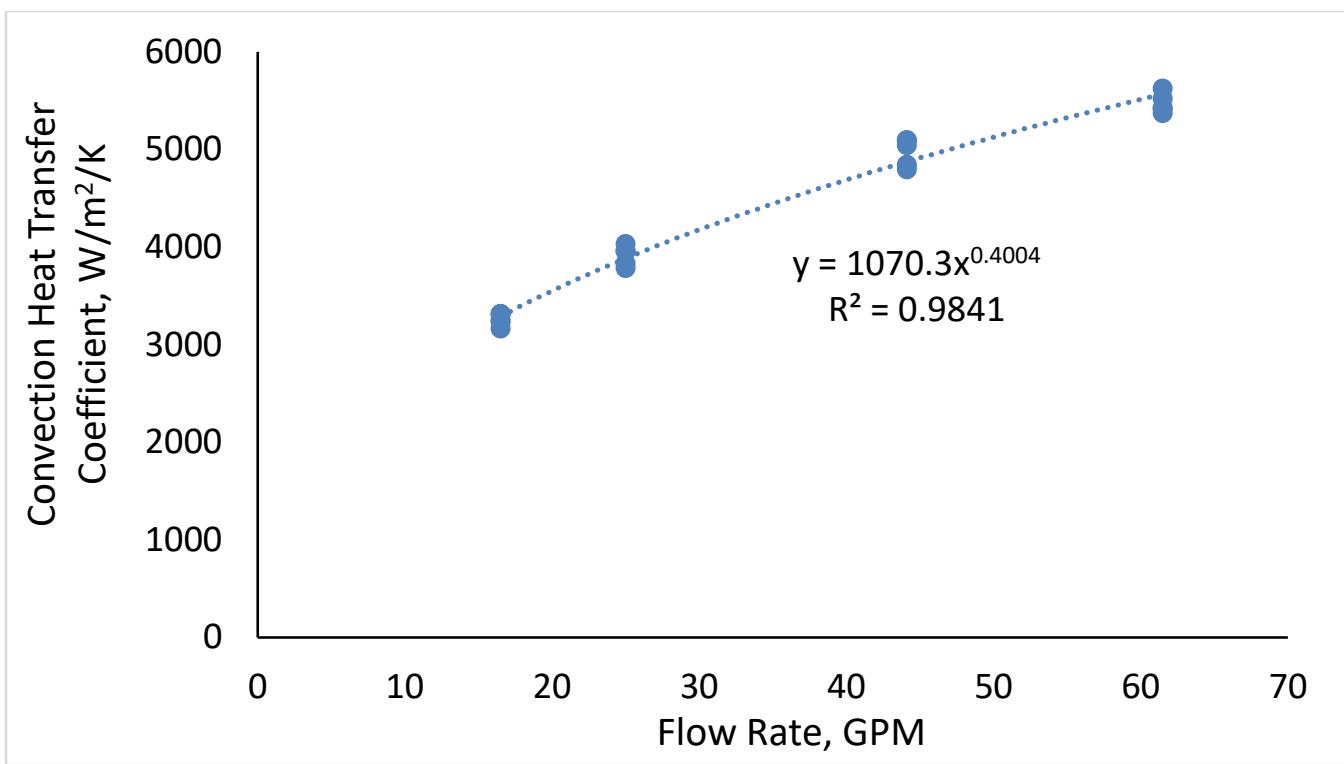

Figure 6. Correlation between the convection heat transfer coefficient and flow rate using a power curve, calculated using November data

\subsubsection{Testing in December 2017}

Tests were conducted at three flow rates. FluxTeq used the measured temperature and heat flux data to determine the flow rate based on the calculated $h$ value and on the correlation derived from the November data (shown in Figure 6). This was a blind test because the actual flow rates were not provided to FluxTeq. Table 1 shows the results (column labeled "First Iteration"). The calculated values were 40 and $7 \%$ lower at 6.8 and $69.7 \mathrm{gpm}$, respectively. However, the calculated value was $16 \%$ higher at $27 \mathrm{gpm}$.

To improve the accuracy of the flow rate calculations, FluxTeq then used a logarithmic curve to establish the correlation between $h$ and the flow rate. It also combined the November and December data (from sensor \#1) to derive the correlation. Figure 7 shows the new correlation.

Table 1. Comparison of flow rates measured with FluxTeq sensor and a commercial flow meter

\begin{tabular}{|c|c|c|c|c|c|}
\hline & \multirow{2}{*}{$\begin{array}{l}\text { Commercial } \\
\text { flow meter, } \\
\text { GPM }\end{array}$} & \multicolumn{2}{|c|}{ First Iteration } & \multicolumn{2}{|c|}{ Second Iteration } \\
\hline & & $\begin{array}{c}\text { FluxTeq, } \\
\text { GPM }\end{array}$ & Difference & $\begin{array}{c}\text { FluxTeq, } \\
\text { GPM }\end{array}$ & Difference \\
\hline $\begin{array}{l}\text { Flow } \\
\text { Rate } 1\end{array}$ & 6.8 & 4.1 & $-40 \%$ & 7.5 & $9.5 \%$ \\
\hline $\begin{array}{l}\text { Flow } \\
\text { Rate } 2\end{array}$ & 27.0 & 31.3 & $16 \%$ & 29.5 & $8.8 \%$ \\
\hline $\begin{array}{l}\text { Flow } \\
\text { Rate } 3\end{array}$ & 69.7 & 64.5 & $-7 \%$ & 68.3 & $-2.1 \%$ \\
\hline
\end{tabular}




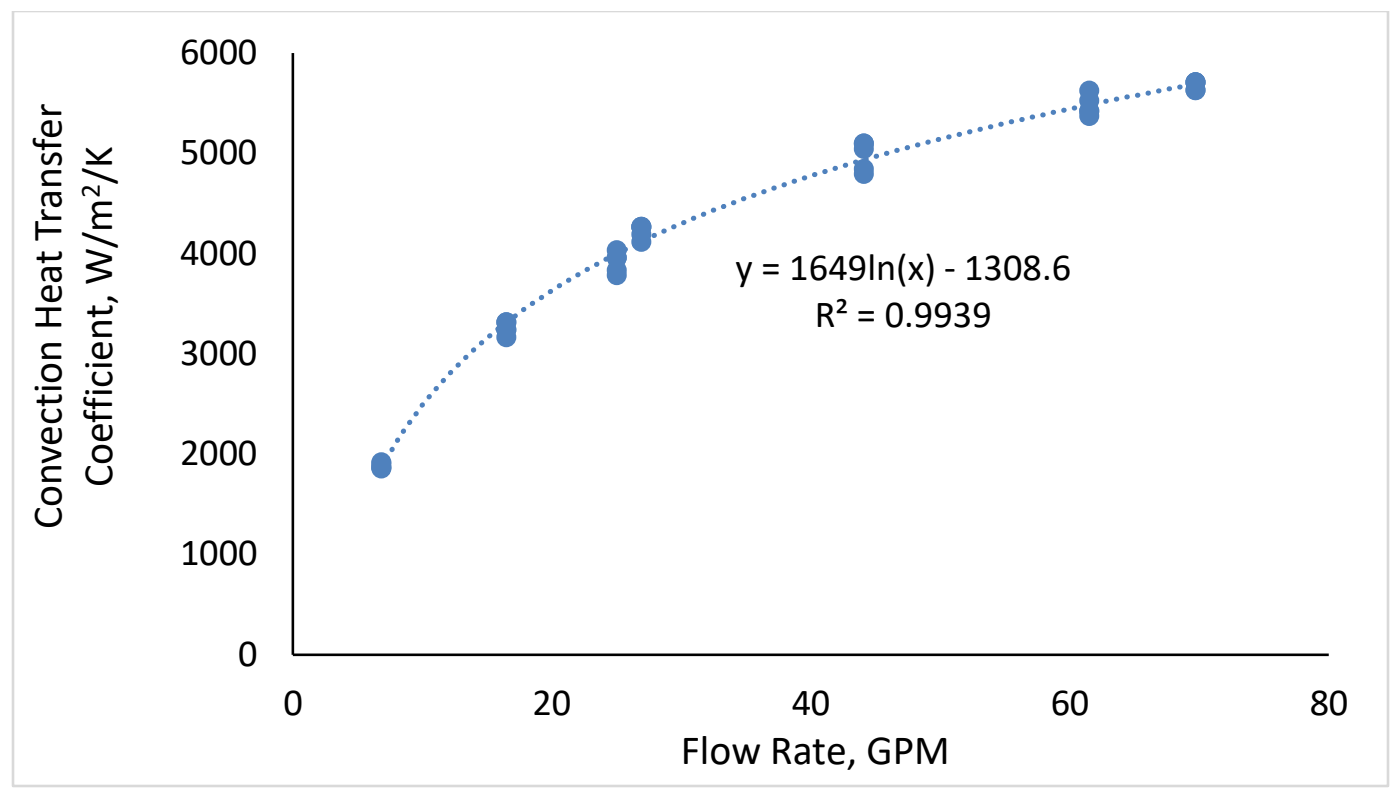

Figure 7. Correlation between the convection heat transfer coefficient and flow rate using a logarithmic curve, calculated using combined November and December data.

Another blind test was conducted and the new correlation was used to determine the flow rates. Table 1 compares the new results (column labeled "Second Iteration") against the results from the first iteration and the flow rates measured with the commercial magnetic flow meter. Between the two methods, flow rates determined using the new correlation (logarithmic curve) produced a smaller error than the flow rates determined using the power curve. With the new correlation, the difference in flow rate measurements between the FluxTeq sensor and the commercial magnetic flow rate sensor was less than $10 \%$. However, that level of error is still higher than the maximum allowed error $(5 \%)$ specified in the new ASTM standard E3137 (ASTM 2018), particularly at low flow rates.

A nondimensional correlation was derived between the measured $h$ and the flow velocity, which was calculated with the flow rate and the cross section area of the pipe. The $h$ was nondimensionalized with the $\mathrm{Nu}$, and the velocity of the flow was nondimensionalized with the Re. Error! Reference source not found.Figure 8 shows the correlation between $N u$ and $R e$ derived based on measured data at the 2 in. copper pipe with water circulating in it. The correlation is very close to the widely accepted Gnielinski correlation (Gnielinski 1976), which is for forced convection in turbulent pipe flow as expressed with Eq. (1). It indicates that the FluxTeq sensor can effectively measure the $h$ inside a pipe and correlate it to the associated flow velocity. The discrepancies at low Re values are thought to be due to increased axial heat loss at the pipe wall and the resulting lower rise in surface temperature in response to the heat input. Since the axial heat loss was ignored in the algorithm for calculating the $h$ value, a lower surface temperature rise will be interpreted as a higher $h$ value (Nu number) than that predicted by the Gnielinski correlation. To improve the accuracy in measuring lower flow rates, the axial heat loss needs to be accounted for. 


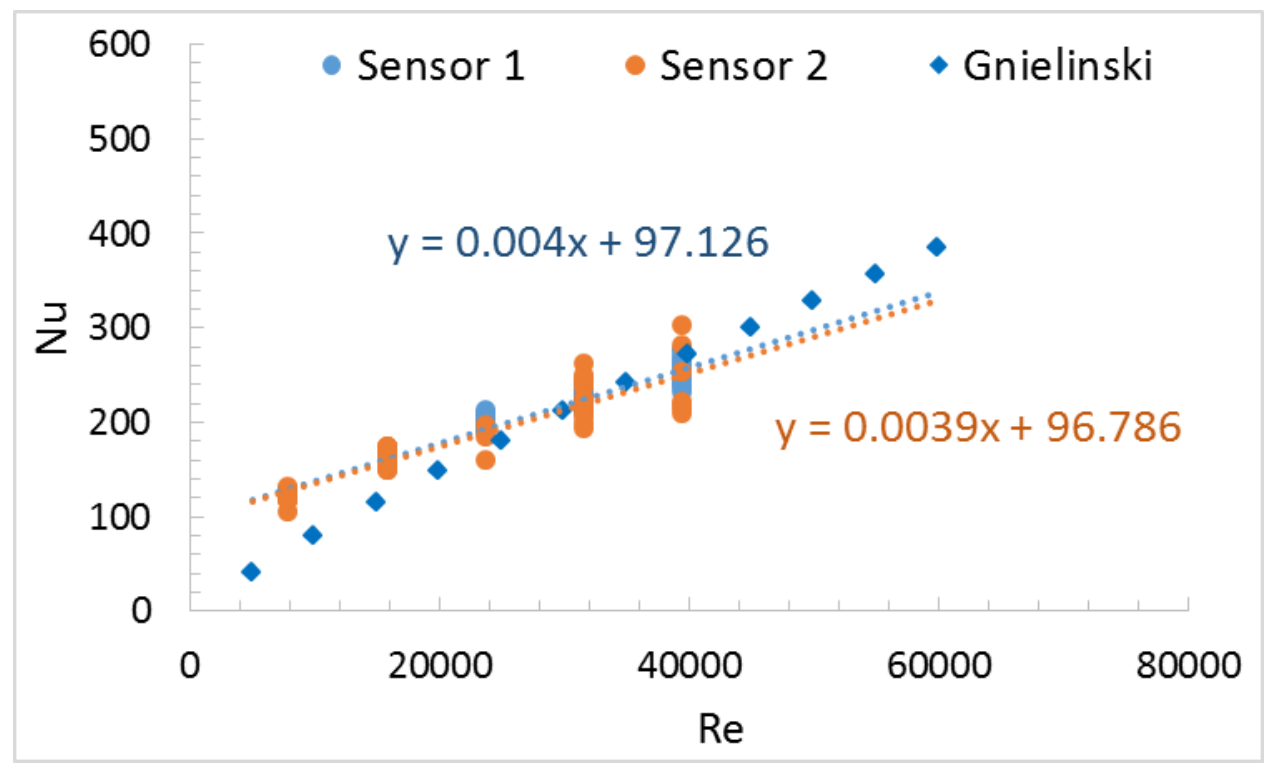

Figure 8. Correlation between $\mathrm{Nu}$ and Re derived from the measured convection heat transfer coefficients and flow velocity in a 2 in. copper pipe with water flowing through it.

$$
N u=\frac{\left(\frac{f}{8}\right)(R e-1000) \times P r}{1+1.27\left(\frac{f}{8}\right)^{0.8}\left(\operatorname{Pr}^{\frac{2}{3}}-1\right)}
$$

Where $f$ is the Darcy friction factor that is calculated by Eq. (2); $N u, R e$, and $\operatorname{Pr}$ (Prandtl number of the fluid) are expressed in Eqs. (3), (4), and (5).

$$
\begin{gathered}
f=[0.79 \times \ln (R e)-1.64]^{-2}, \\
R e=\frac{D V}{\vartheta}, \\
N u=\frac{h D}{K}, \\
\operatorname{Pr}=\frac{\vartheta}{\alpha},
\end{gathered}
$$

where $D$ is the inside diameter of the pipe, $V$ is the average velocity of the fluid, $\vartheta$ is the kinematic viscosity of the fluid, $K$ is the thermal conductivity of the fluid, and $\alpha$ is the thermal diffusivity of the fluid. The Gnielinski correlation is valid when $0.5 \leq \operatorname{Pr} \leq 200$ and $300 \leq \operatorname{Re} \leq 5 \times 10^{6}$.

\subsubsection{Testing of Second-Generation Prototype}

One issue observed during these tests was varying $R$ between the TCs and the pipes among the identical sensors. We thought that one major cause of the variation was nonuniform pressure on the sensors from the compression wraps. Therefore, FluxTeq designed a clamping system to ensure uniform pressure on the sensor and thereby to ensure consistent $R$ between the TCs and the pipes. Sensors with this type of clamp were designated as second prototype sensors (shown in Figure 9). The new sensor package included a pre-assembled heater, heat flux sensor, and TC. The sensor package could be wrapped on the surface of a pipe and secured with a clamp; therefore, its installation was significantly faster and easier. 


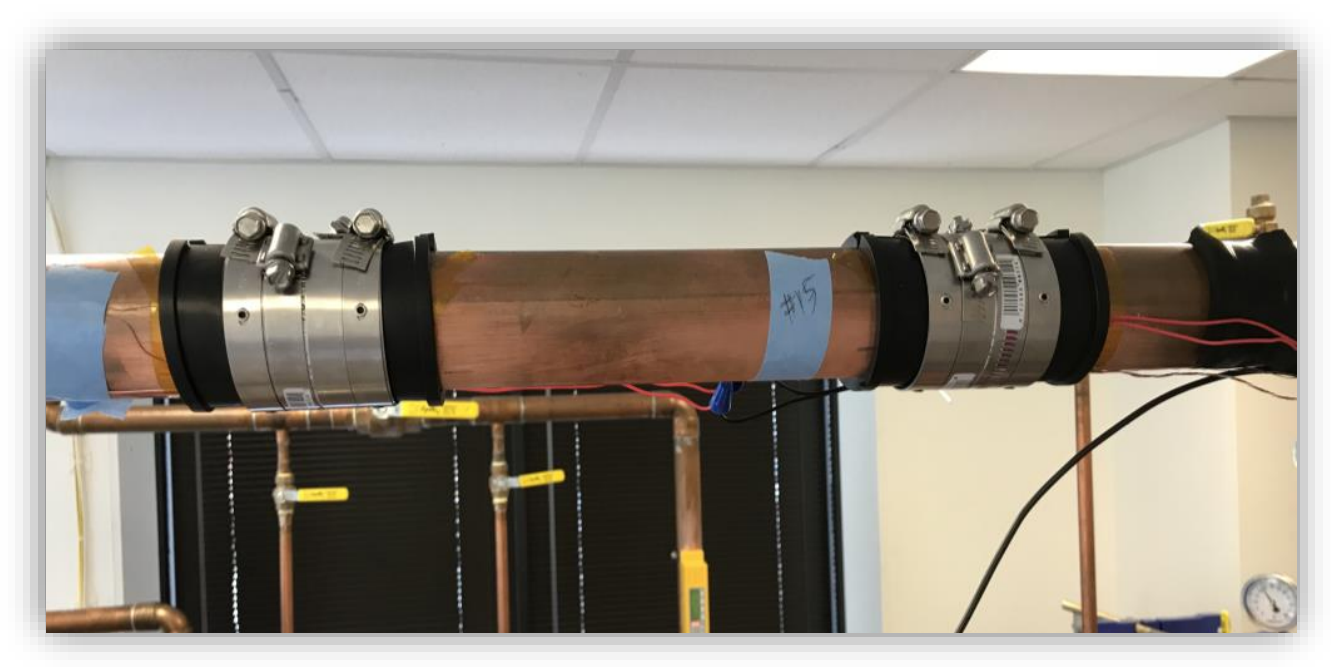

Figure 9. Second prototype FluxTeq sensors (prefabricated and easier to install).

Eight sets of the second prototype FluxTeq flow meter were installed on the experimental hydronic piping system. Two sensors were installed on each of the three copper pipe sections with difference diameters $(2$, 1.25 , and 1 in.) that used water as the heat carrier liquid. Another two sensors were installed on a 2 in. copper pipe section in another hydronic piping system in which a mixture of water and glycol was circulated. Test results indicated that the second prototype improved the consistency of the sensor measurement (i.e., there was less variation between the measurements by the two sensors installed on the same pipe). Reinstalling the new sensors had little or no effect on the results.

Further tests were performed on pipes with different diameters and with different types of fluids. The correlations between the $\mathrm{Nu}$ and the Re were derived from the test data. As shown in Figure 10, the correlations were not sensitive to pipe size if the fluid was the same (e.g., water in all pipes), so the same correlation could be used to measured flow rates in pipes with different diameters. However, the correlation was quite different for different types of fluids (e.g., glycol in some pipes, water in others) even if the pipe diameters were the same. For a given Re number, the Nu number for a glycol solution was higher than the $\mathrm{Nu}$ for water. That result was consistent with the Gnielinski correlation because a glycol solution has a larger Prandtl number (Pr) than water due to its high viscosity. 


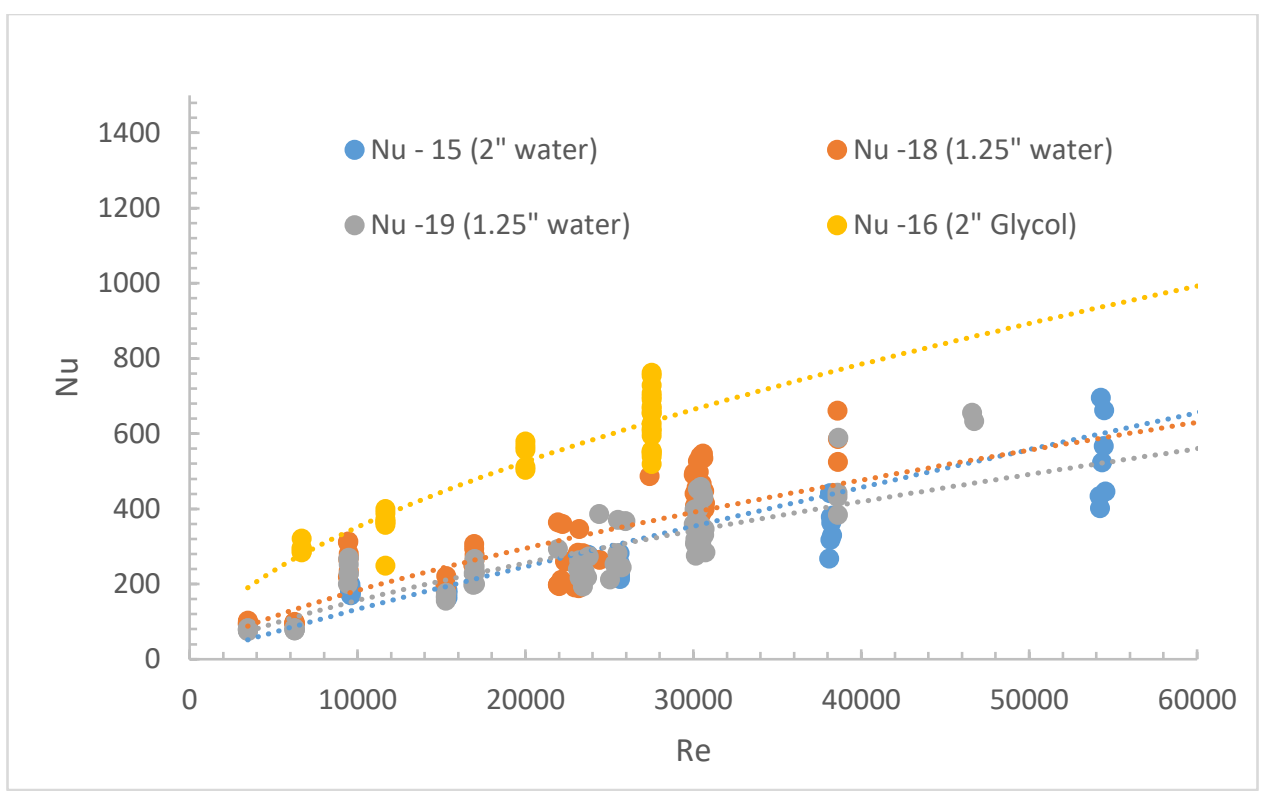

Figure 10. Correlation between $\mathrm{Nu}$ and Re derived from the measured convection heat transfer coefficients and flow rates on copper pipes with different diameters and fluid types.

Figure 10 also shows wide variations in measured $h$ for a given flow rate. This variation may be due to the parameter estimation algorithm used to determine $R$ and $h$. That algorithm may have found several combinations of $R$ and $h$ that could minimize the RSME (root mean square error) between the measured and the calculated sensor temperature, but not the actual physical values of $R$ and $h$.

\section{SUBJECT INVENTIONS (AS DEFINED IN THE CRADA)}

FluxTeq developed an inexpensive, nonintrusive flow rate sensor, which is the most important component of a BTU meter or a flow meter. Each sensor package consisted of a FluxTeq standard heat flux sensor product, TC temperature sensor, and thin-film resistance heater (Figure 11). The sensor package was flexible and thus was easily mounted on the outside surfaces of pipes using a compression wrap or clamping tool.

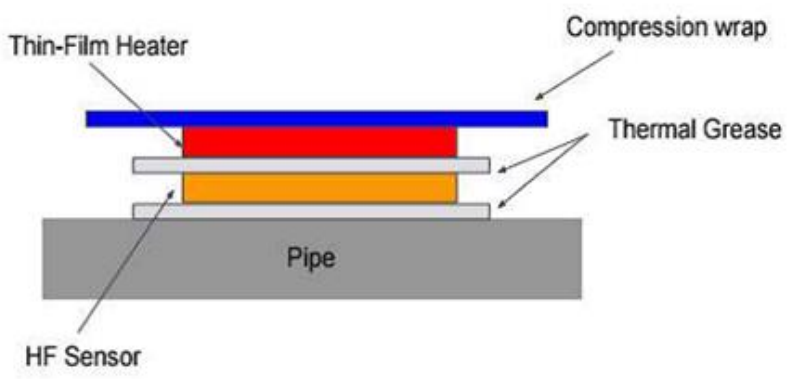

Figure 11. The sensor configuration.

The flow rate sensor could operate in a couple of different configurations, either intermittently or continuously. The first design, which is used in the current prototype, operated intermittently by creating a small thermal event for a short duration of time using power supplied to the resistance heater. The heat flux and temperature responded to this thermal event on the outer surface of the pipe. Heat flux and 
temperature data were first recorded while the heat was turned off. These initial data provided information that was used to determine the temperature of the internal fluid as well as a heat transfer baseline. The heater, powered by a small battery or low-voltage power source, was then turned on, providing a heat flux into the pipe and fluid flow. The second system configuration could include an additional independent heat flux sensor and/or temperature sensor upstream to determine internal flow temperature. This additional sensor could enable the system to provide continuous BTU and flow rate measurements, as opposed to the intermittent testing described in the single sensor configuration.

In either of the described system configurations, both the transient and steady state thermal responses of heat flux and temperature were measured by the sensor and contributed to the determination of the flow rate value. The measured heat flux and temperature response signals are directly dependent on the $h$ of the fluid flowing in the pipe. Since the $h$ is related to the velocity of the internal fluid, correlations are created that relate the measured $h$ values to the fluid velocities. With additional information, such as pipe diameter and fluid type that is supplied by the user, the sensor can determine the mass flow rate and heat transfer rate of a heat exchanger.

\section{COMMERCIALIZATION POSSIBILITIES}

Current BTU or flow meters use either intrusive sensors that are difficult to install or the sophisticated nonintrusive ultrasonic sensors that are expensive. The proposed BTU meter takes a novel approach in collecting measurements using thermal sensors to determine flow rate within a pipe. The estimated price point of the FluxTeq flow rate sensor is around \$250, which is at least $50 \%$ lower than the flow meters currently available on the market (Figure 12). Installation costs for the intrusive meters could be much higher than the cost of the meter itself for existing systems because they need a specialized technician that can freeze the flow to stop the fluid flowing out of the pipe.

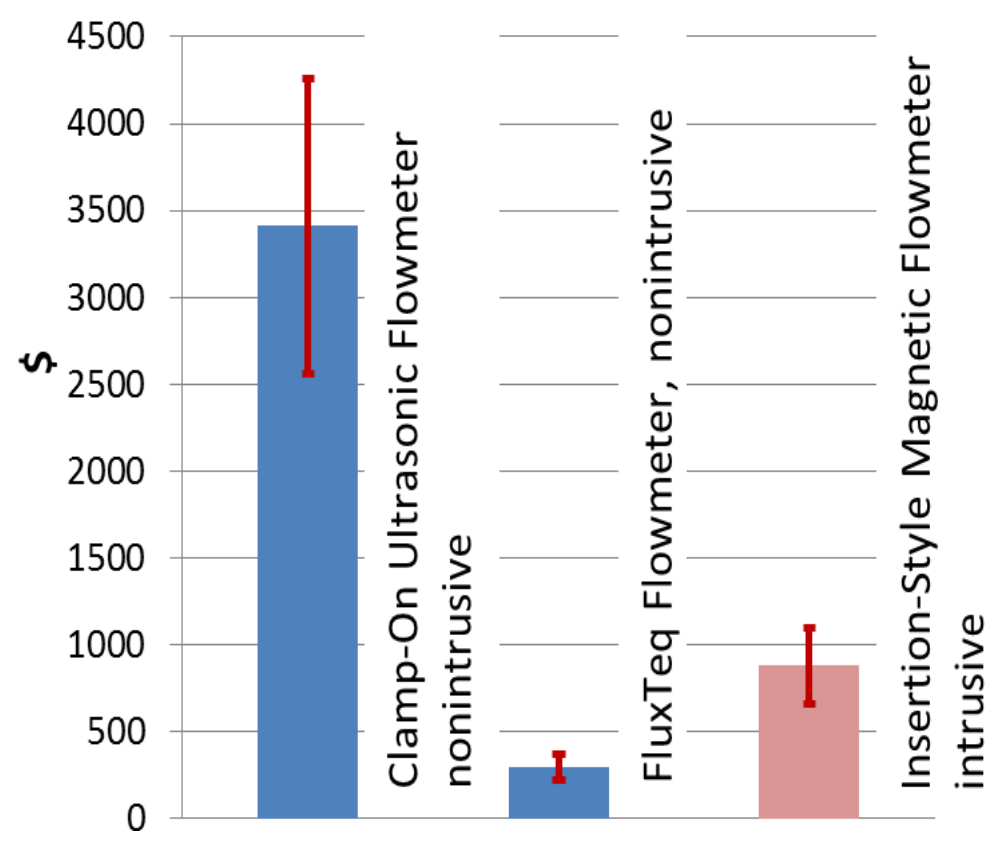

Figure 12. Approximate price range of various flow meters. Each column indicates the average price of flow meters in each category, and the error bars show the range of the price.

As shown in Table 1, the difference between the flow rates measured with the FluxTeq flow rate sensor and a commercial magnetic flow meter is less than $10 \%$. This indicates that the FluxTeq flow rate sensor has accuracy comparable to that of the nonintrusive ultrasonic flow meters (3-10\%) listed in 
Table 2. ${ }^{1}$ Furthermore, the nonintrusive nature of the system makes it easy to install for any building manager or technician. BTU meters employing FluxTeq's flow rate sensor will cost a fraction of current systems on the market and provide comparable performance. The new technology will enable widespread use of BTU meters in HVAC control systems and thus help reduce energy consumption in buildings.

Table 2. Comparison of existing commercially available flow meters.

\begin{tabular}{|c|c|c|c|c|}
\hline Туре & $\begin{array}{c}\text { Meter } \\
\text { cost }\end{array}$ & Accuracy & Pros & Cons \\
\hline Coriolis & $\$ \$ \$$ & $0.05 \%$ & $\begin{array}{l}\text { Measures mass flow, } \\
\text { liquid density. and } \\
\text { temperature } \\
\text { Unaffected by changes } \\
\text { in temperature and } \\
\text { pressure }\end{array}$ & $\begin{array}{l}\text { - High pressure drop } \\
\text { and noise } \\
\text { - Low flow rates may } \\
\text { result in lower } \\
\text { measurement } \\
\text { accuracy }\end{array}$ \\
\hline Magnetic & $\$ \$$ & $0.15 \%$ & $\begin{array}{l}\text { - } \\
\text { not constrained by } \mathrm{Re} \\
\text { - } \\
\text { Immuner } \\
\text { changes } \\
\text { - Negligible pressure } \\
\text { loss }\end{array}$ & $\begin{array}{l}\text { Unable to measure } \\
\text { gases } \\
\text { Fluid conductance } \\
>5 \mu \mathrm{S} \text { is required }\end{array}$ \\
\hline Turbine & $\$$ & $0.25 \%$ & $\begin{array}{l}\text { - High repeatability } \\
\text { - High pressure and } \\
\text { temperature tolerance } \\
\text { - } \quad \text { Fast response rate }\end{array}$ & $\begin{array}{l}\text { Two-phase flows } \\
\text { may cause } \\
\text { inaccuracies } \\
\text { - Frequent } \\
\text { maintenance required }\end{array}$ \\
\hline Vortex & $\$ \$$ & $2 \%$ & $\begin{array}{l}\text { - Performs in extreme } \\
\text { conditions } \\
\text { No field calibration } \\
\text { required }\end{array}$ & $\begin{array}{l}\text { - Not for low-flow } \\
\text { applications } \\
\text { Unsuitable for high- } \\
\text { viscosity fluids } \\
\text { Inaccurate in high- } \\
\text { vibration } \\
\text { environments }\end{array}$ \\
\hline Ultrasonic & $\$ \$ \$$ & $\begin{array}{l}3-10 \% \\
\text { (nonintrusive) }\end{array}$ & $\begin{array}{ll}\text { - } & \text { For both liquids and } \\
\text { gases } \\
\text { - } & \text { Reduced maintenance } \\
\text { - } & \text { No pressure drop }\end{array}$ & 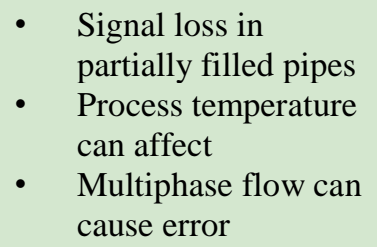 \\
\hline
\end{tabular}

\section{PLANS FOR FUTURE COLLABORATION}

Tests performed in this project showed promising results for the innovative flow rate sensor developed by FluxTeq. However, a few technical limitations of the prototype flow rate sensor were encountered during this project, including relatively low accuracy (up to $10 \%$ of actual flow rate); inconsistent flow rate

\footnotetext{
${ }^{1}$ Based on information presented at http://www.flowsolutionsblog.com/blog/comparing-flow-meter-technologychoosing-the-meter/.
} 
measurements from different cycles of heat impulse; incapable of determining the flow rate at real-time on site. In addition, it is not clear whether the sensor can work with pipe materials other than copper. Future research collaborations are being planned outside of this project to address the above limitations. The planned future collaborations include:

- Develop a dedicated processor to analyze the measured temperature and heat flux data and determine the flow rate in real time and onsite. This data processor is an necessity to integrate the flow rate sensor into a building energy management system or an HVAC control system.

- Improve the repeatability of the flow rate measurement by refining the algorithm for determining the $h$.

- Further develop the sensor to account for temperatures change in the flow resulting from rapid changes in heat input from other resources than the built-in resistance heater (e.g., the on/off operation of a heat pump) during a test cycle

- Integrate the above improved flow rate sensor into a building energy monitoring system or a HVAC control system to evaluate its performance, including accuracy, repeatability, response rate, and tolerance for varying flow rate and temperature

\section{CONCLUSIONS}

The FluxTeq flow rate sensor takes an innovative thermal measurement approach to determining flow rate in an nonintrusive way at low cost. Test results from this project indicate that the new sensor can measure flow rates of different fluids in copper pipes of various sizes. The difference between the flow rate measurements conducted with the new sensor and with a calibrated commercial magnetic flow meter is less than $10 \%$. Although the accuracy of the current prototype does not meet the requirements of ASTM standard E3137 (maximum allowed error 5\%), it is comparable to the accuracy of the nonintrusive ultrasonic flow meters $(3-10 \%)$. The estimated price of the FluxTeq flow rate sensor is around $\$ 250$, which is at least $50 \%$ lower than the average price of other flow meters currently available on the market. However, to make commercializable new flow meters and new BTU meters using the flow rate sensor, the following developments are needed:

- Increase accuracy and repeatability of flow rate measurement

- Enable real-time measurement

- Enable use with variable flow rates and temperatures

- Enable use with pipe materials other than copper

\section{REFERENCES}

Alshawaf, H. 2018. A Novel Thermal Method for Pipe Flow Measurements Using a Non-invasive BTU Meter, Virginia Tech, Master Thesis, May 9, 2018

EIA (Energy Information Administration). 2018a. Residential Energy Consumption Survey (RECS). Available at https://www.eia.gov/consumption/residential/; accessed September 2018.

EIA (Energy Information Administration). 2018b. Commercial Buildings Energy Consumption Survey (CBECS). Available at https://www.eia.gov/consumption/residential/; accessed September 2018.

Gnielinski, V., 1976. New equations for heat and mass transfer in turbulent pipe and channel flow. Int. Chem. Eng. 16 (2). 
Treado, Stephen, and Yan Chen. 2013. "Saving Building Energy through Advanced Control Strategies." Energies 6(9), 4769-4785. doi:10.3390/en6094769

ASTM (American Society for Testing and Materials). 2018. Standard Specification for Heat Meter Instrumentation. ASTM E3137/E3137M-18, ASTM International, West Conshohocken, PA. Available at https://www.astm.org/Standards/E3137.htm; accessed September 2018. 